\title{
Estimation of stature from hand and handprint measurements in a sample of Sri Lankan Sinhalese population
}

\author{
Ekanayake $\mathrm{SD}^{1}{ }^{*}$, Nandasena $\mathrm{T}^{1}$, Nawarathna $\mathrm{LS}^{2}$, Alahakoon $\mathrm{S}^{1}$, Ariyasinghe $\mathrm{S}^{1}$, \\ Arambawatta $\mathrm{AKS}^{1}$, Nanayakkara $\mathrm{CD}^{1}$ \\ ${ }^{I}$ Department of Basic Sciences, Faculty of Dental Sciences, University of Peradeniya. \\ ${ }^{2}$ Department of Statistics and Computer Science, Faculty of Science, University of \\ Peradeniya. \\ *samithade@gmail.com
}

Stature is an essential attribute in creation of a biological profile in forensic anthropometry.

Anthropometric approaches of the hand and handprint measurements in forensic investigations have been widely demonstrated. Hence, the present study was undertaken to estimate stature from hand and handprint measurements using sex specific regression models in a group of Sri Lankan Sinhalese. A sample comprising of 51 males and 66 females belonging to the Sinhalese ethnic group in the age range of 20 to 28 years was recruited in the study. Stature and eight measurements of both hands and their corresponding prints were collected and recorded using standard instruments and techniques. Significant positive correlation was shown between all hand and handprint measurements and stature $(p<0.05$ $\mathrm{p}<0.001)$ in both sexes. Simple linear regression equations showed a stature prediction accuracy ranging from \pm 4.41 to $\pm 5.88 \mathrm{~cm}$ and \pm 4.04 to $\pm 5.22 \mathrm{~cm}$ for hand measurements in males and females respectively. Corresponding figures for handprint measurements were $\pm 4.57 \mathrm{~cm}$ to $\pm 5.95 \mathrm{~cm}$ and \pm 4.36 to $\pm 5.52 \mathrm{~cm}$, respectively while multiple regression models derived from hand measurements showed superior stature prediction accuracy rates $( \pm 3.95 \mathrm{~cm}$ in males and $\pm 3.82 \mathrm{~cm}$ in females). The present study demonstrates that stature can be predicted from hand and handprint measurements with higher accuracy rates than those recorded in previous studies for other population groups. Hence, the stature prediction models established in this study will be useful in disaster victim identification from mutilated human remains and in crime scene investigations in Sinhalese population in Sri Lanka. 